\title{
CARACTERIZAÇÃO DE UM AÇO SAE 1016 APÓS TEMPERA, TEMPERA INTERCRÍTICA E NORMALIZAÇÃO *
}

\author{
Dyego Irineu Silva de Almeida ${ }^{1}$ \\ Gilvania Katia Cruz Pinheiro² \\ Yanka Maria Araújo Torres ${ }^{3}$ \\ Mário José Maia Leitão 4 \\ Marcelo José Gomes da Silva
}

\section{Resumo}

O presente trabalho foi proposto em sala de aula, na disciplina de tratamento térmico de ligas metálicas, do curso de Engenharia Metalúrgica da Universidade Federal do Ceará e teve como objetivo comparar as diferenças entre microestruturas e propriedades de um aço SAE 1016 após os tratamentos térmicos de normalização, têmpera e têmpera intercrítica. Três amostras do mesmo material foram tratadas termicamente. Uma amostra foi normalizada, outra temperada e outra temperada na zona intercrítica e após as análises metalográficas e ensaios de dureza foi possível concluir que a amostra normalizada apresentou uma microestrutura ferrítica com ilhas de perlita, a amostra temperada a $930^{\circ} \mathrm{C}$ apresentou microestrutura martensítica e a amostra temperada na zona intercrítica formou microestrutura bainítica em uma matriz ferrítica.

Palavras-chave: Normalização; Têmpera; SAE 1016.

\section{CHARACTERIZATION OF A SAE 1016 STEEL AFTER QUENCHING, INTER CRITICAL QUENCHING AND NORMALIZATION}

\section{Abstract}

The present work was proposed in the classroom of the metal alloys thermal treatment course of the Metallurgical Engineering course of the Federal University of Ceará and aimed to compare the differences between microstructures and properties of a SAE 1016 steel after the thermal treatments of Normalization, tempering and intercritical tempering. Three samples of the same material were heat treated. A sample was normalized, another tempered and another tempered in the intercritical zone. After the metallographic analysis and hardness tests, it was possible to conclude that the normalized sample had a ferritic microstructure with perlite islands, the sample tempered at $930^{\circ} \mathrm{C}$ showed martensitic microstructure and Sample tempered in the intercritical zone formed bainitic microstructure in a ferritic matrix.

Keywords: Quenching; Normalization; SAE 1016.

1 Engenharia Metalúrgica/graduando, bolsista de iniciação científica, Departamento de Engenharia Metalúrgica e Materiais, Universidade Federal do Ceará, Fortaleza, Ceará e Brasil.E-mail: sodyego@gmail.com

2 Engenharia Metalúrgica/graduando, voluntário de iniciação científica, Departamento de Engenharia Metalúrgica e Materiais, Universidade Federal do Ceará, Fortaleza, Ceará e Brasil, Email: gilvaniakatia@gmail.com

3 Engenharia Metalúrgica/graduando, voluntário de iniciação científica, Departamento de Engenharia Metalúrgica e Materiais, Universidade Federal do Ceará, Fortaleza, Ceará e Brasil. Email: yankaaraujo11@gmail.com

4 Engenharia Metalúrgica/graduando, bolsista de iniciação científica, Departamento de Engenharia Metalúrgica e Materiais, Universidade Federal do Ceará, Fortaleza, Ceará e Brasil E-mail: maialeitao@gmail.com

5 Engenharia Metalúrgica, Doutor, Professor, Departamento de Engenharia Metalúrgica e de Materiais, Universidade Federal do Ceará, Fortaleza, Ceará, Brasil E-mail: mgsilva@ufc.br 


\section{INTRODUÇÃO}

O aço SAE 1016 é considerado um aço com baixo teor de carbono e por isso possui baixa temperabilidade. Temperabilidade é a influência da composição da liga sobre a habilidade de um aço se transformar em martensita para um tratamento de têmpera específico [1].

Dessa forma fica difícil endurece-lo por tratamento térmico, tendo em vista que seria necessário um meio com severidade de têmpera muito alta. Além da dificuldade de se temperar, o material apresentaria uma martensita de dureza média, por conta do baixo teor de carbono.

A têmpera consiste em resfriar o aço, após austenitização, a uma velocidade suficientemente rápida para evitar as transformações difusionais na peça em questão. Deste modo, obtém-se estrutura metaestável martensítica [2].

Uma tentativa para elevar a dureza de aços desse tipo é fazer uma têmpera na zona intercrítica, entre as linhas $A 1$ e $A 3$ do diagrama ferro carbono. Na região bifásica, coexistiriam ferrita primária e austenita rica em carbono. Ao resfriar bruscamente, espera-se uma microestrutura de matriz ferrítica com ilhas de martensita de alto teor de carbono com dureza elevada.

A normalização consiste no aquecimento do aço a uma temperatura acima da zona crítica, seguido de resfriamento ao ar [3]

\section{MATERIAIS E MÉTODOS}

Neste trabalho foram utilizadas três amostras de um aço SAE 1016. A composição química típica do aço é mostrada na Tabela 1. A Tabela 2 apresenta a composição química do aço utilizado nesse trabalho.

Tabela 1. Composição química típica do aço SAE 1016 em \% em massa

\begin{tabular}{c|cccc}
\hline & $C$ & $M n$ & $P$ & $S$ \\
\hline Mín & 0,13 & 0,60 & - & - \\
Max & 0,18 & 0,90 & 0,040 & 0,050
\end{tabular}

Fonte: ASM HANDBOOK .

Tabela 2. Composição química do aço utilizado nesse trabalho analisado em espectrômetro de emissão ótica Shimadzu PDA-7000.

\begin{tabular}{c|cccc}
\hline & $C$ & $M n$ & $P$ & $S$ \\
\hline Composição média & 0,14 & 0,67 & 0,021 & 0,017 \\
\hline
\end{tabular}

Fonte: Elaborado pelos autores.

As amostras foram cortadas, em seguida colocadas em um forno a $930{ }^{\circ} \mathrm{C}$ por um período de uma hora. Após esse tempo uma amostra foi resfriada em água sob agitação, outra foi resfriada ao ar calmo e a última permaneceu dentro do forno que teve sua temperatura ajustada para $770 \stackrel{\circ}{ } \mathrm{C}$ e depois de 10 minutos nessa temperatura foi resfriado em água sob agitação.

Após tratadas, as amostras foram embutidas em baquelite, lixadas, polidas com alumina e atacadas com NITAL $2 \%$. Em seguida, foram tiradas as fotos em um microscópio óptico. Foram feitas imagens de MEV na amostra temperada na zona intercrítica. 
Por fim, foi realizado ensaio de dureza Vickers em 5 pontos distintos em cada amostra, utilizando uma carga de 10Kgf.

\section{RESULTADOS E DISCUSSÃO}

A figura 1 apresenta a microestrutura da amostra normalizada. Nela, é possível observar uma matriz ferrítica, em tom mais claro e ilhas de perlita em tom escuro.
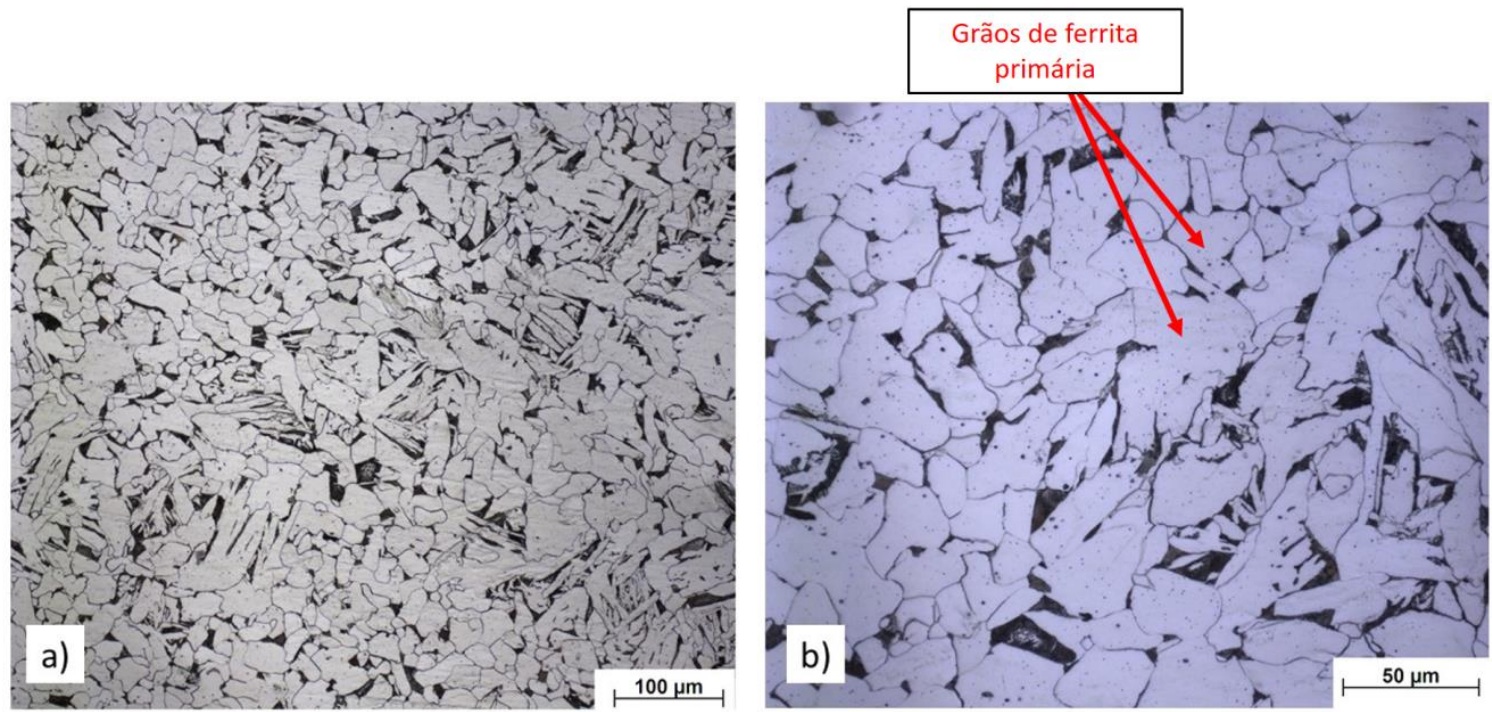

Figura 1. (a) Micrografia da amostra normalizada, ataque NITAL $2 \%$, ampliação 200X (b) Micrografia da amostra normalizada, ataque NITAL 2\%, ampliação 500X.

Fonte: Elaborado pelos autores.

$\mathrm{Na}$ figura 2 observa-se a microestrutura da amostra temperada a partir de $930^{\circ} \mathrm{C}$. Nessa micrografa vê-se uma microestrutura tipicamente martensítica.
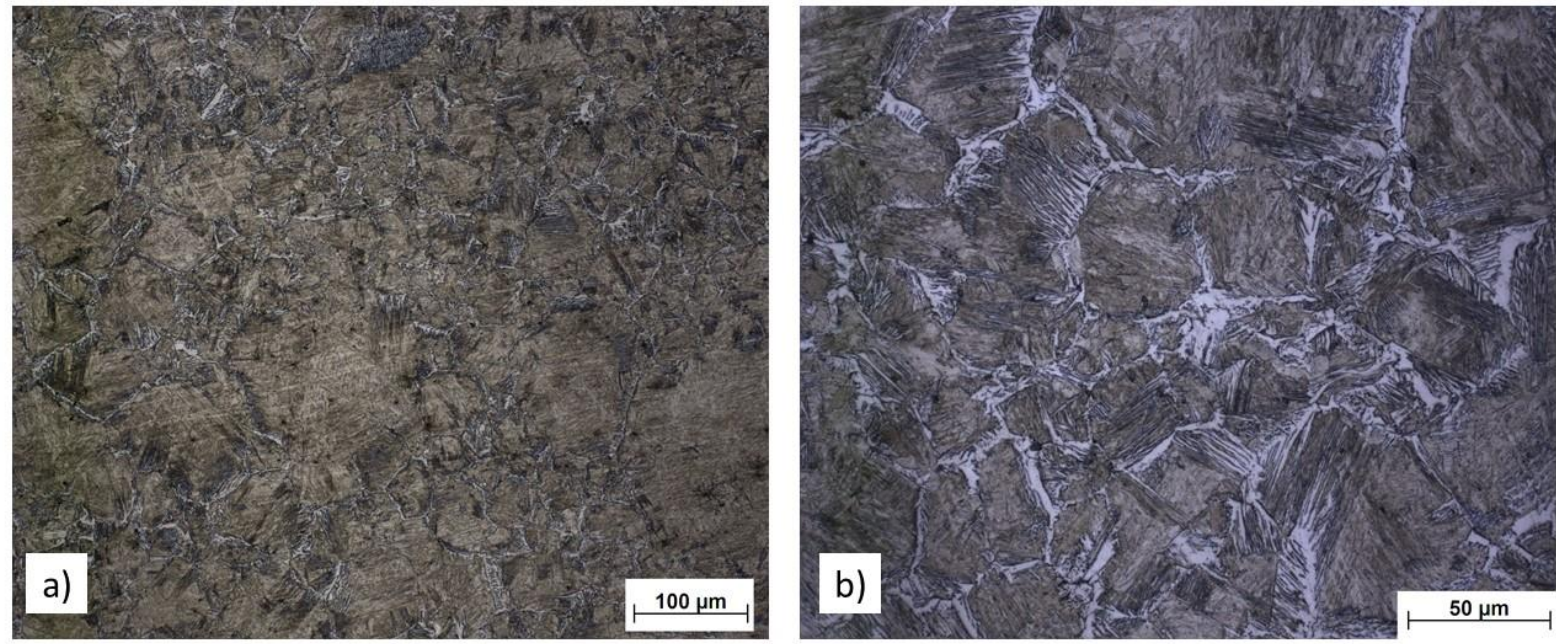

Figura 2. (a) Micrografia da amostra temperada, ataque NITAL $2 \%$, ampliação $200 \mathrm{X}$ (b) Micrografia da amostra temperada, ataque NITAL $2 \%$, ampliação $500 \mathrm{X}$.

Fonte: Elaborado pelos autores. 
A figura 3 apresenta as micrografias da amostra temperada na zona intercrítica. É possível identificar pelo menos três fases distintas, ferrita primária, martensita e possivelmente bainita.
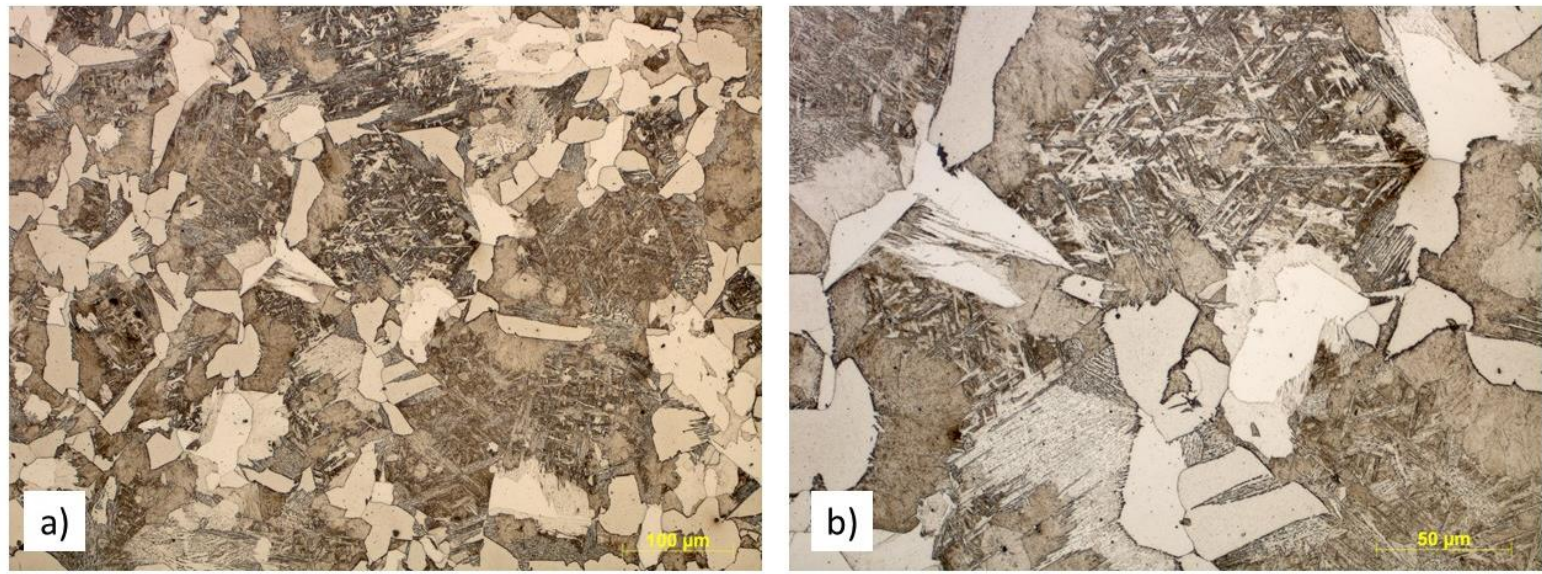

Figura 3. (a) Micrografia da amostra temperada na zona intercritica, ataque NITAL $2 \%$, ampliação 200X. (b) Micrografia da amostra temperada na zona intercritica ataque NITAL 2\%, ampliação 500X.

Fonte: Elaborado pelos autores

A intenção de realizar esse tratamento foi formar uma matriz ferrítica com ilhas de martensita, porém, provavelmente por estar, antes do resfriamento, em uma temperatura de $770 \stackrel{\circ}{ } \mathrm{C}$, bem menor que os $930 \stackrel{\circ}{\mathrm{C}}$ do outro tratamento, não se formou apenas martensita e uma parte da austenita se transformou em bainita. A figura 4 mostra com mais detalhes os microconstituintes dessa amostra.
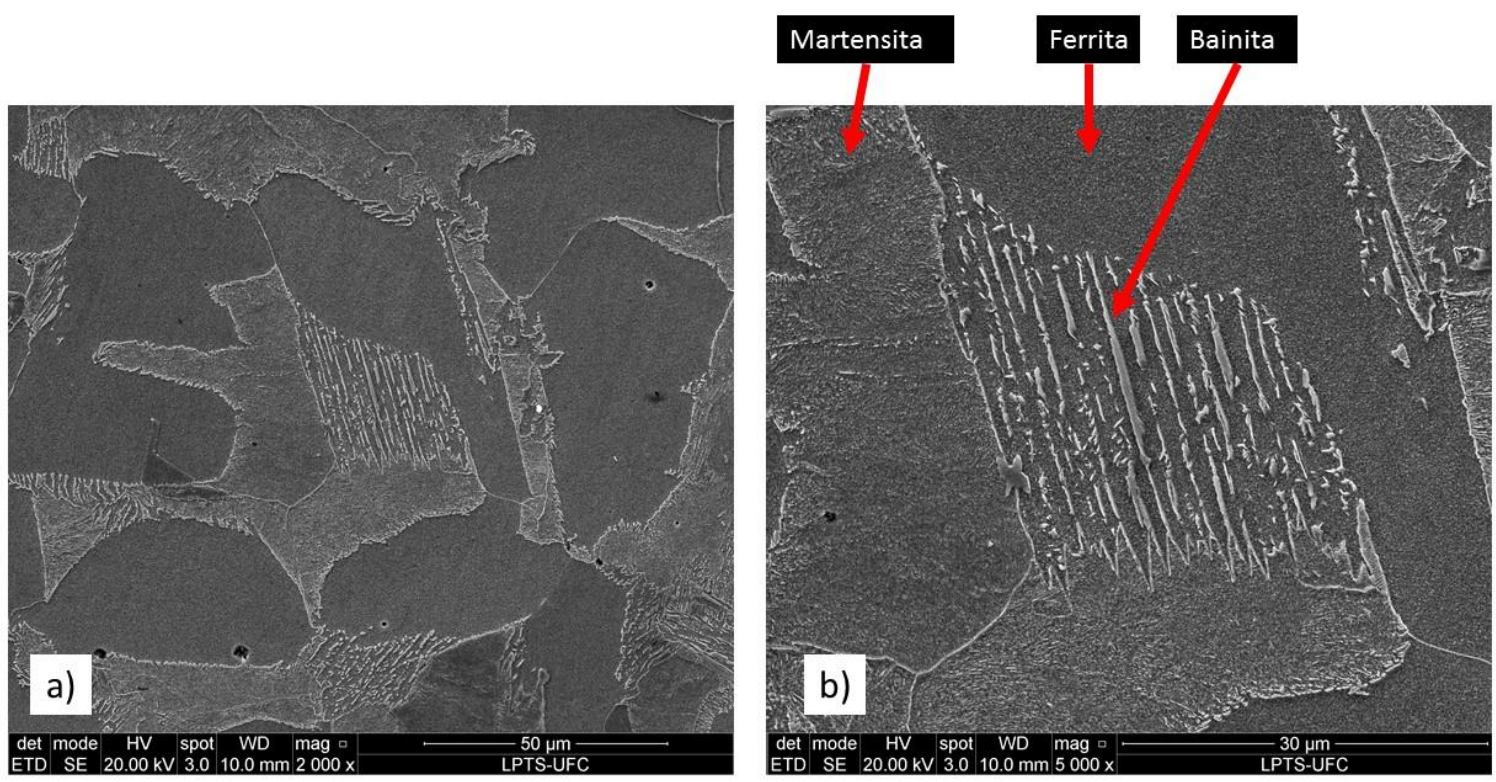

Figura 4. (a) Micrografia da amostra temperada na zona intercrítica, ataque NITAL $2 \%$, ampliação 2.000X. b) Micrografia da amostra temperada na zona intercrítica, ataque NITAL $2 \%$, ampliação 5.000X.

Fonte: Elaborado pelos autores. 
Também foi realizado um ensaio de dureza para fazer uma comparação entre as amostras e os tratamentos. A tabela 3 apresenta os valores obtidos no ensaio de ureza Vickers.

Tabela 3. Resultados obtidos no ensaio de dureza Vickers.

\begin{tabular}{|c|c|c|c|}
\hline & Normalizada (HV) & Temperda (HV) & $\begin{array}{c}\text { Temperada na zona } \\
\text { intercrítica }(\mathrm{HV})\end{array}$ \\
\hline Ponto 1 & 132,28 & 301,19 & 227,08 \\
\hline Ponto 2 & 126,85 & 328,13 & 235,16 \\
\hline Ponto 3 & 125,54 & 322,72 & 227,08 \\
\hline Ponto 4 & 125,22 & 342,24 & 214,99 \\
\hline Ponto 5 & 131,23 & 322,72 & 210,70 \\
\hline Média & 128,22 & 323,40 & 223,00 \\
\hline
\end{tabular}

Fonte: Elaborado pelos autores.

A figura 5 mostra um gráfico comparativo entre as médias das durezas das amostas.

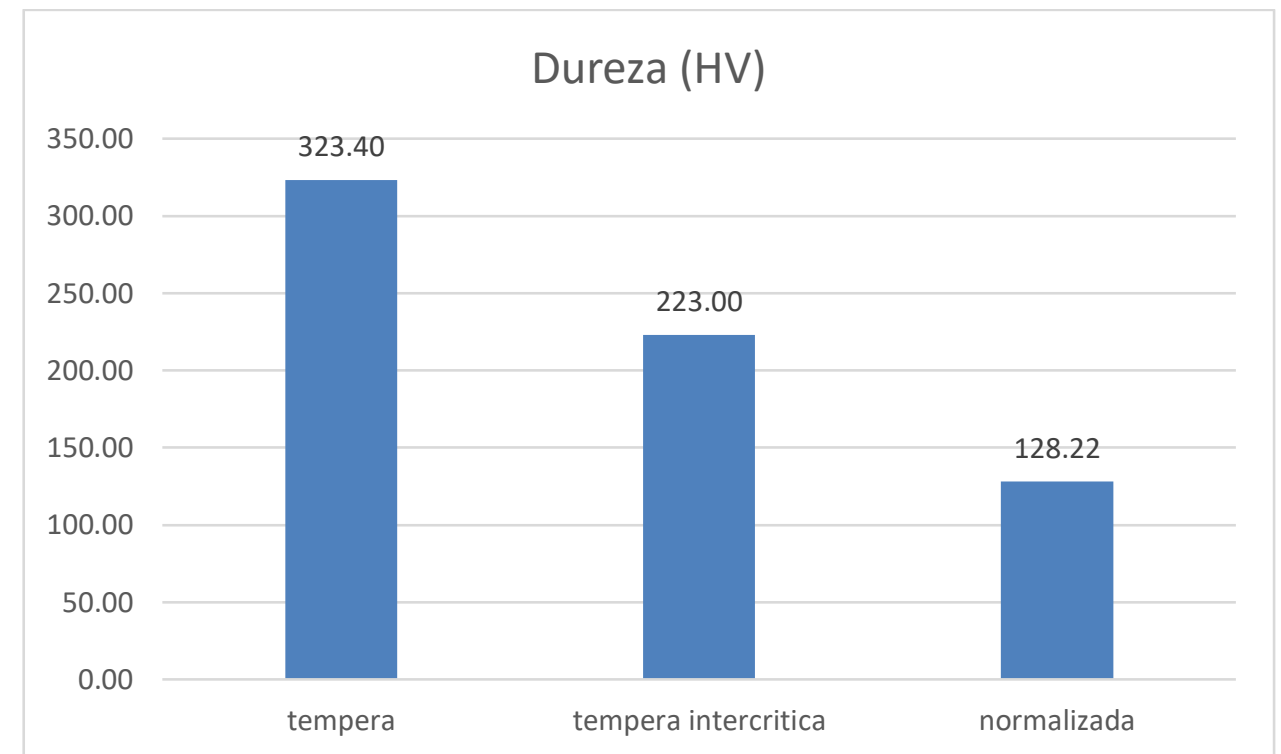

Figura 5. Gráfico comparativo entre as durezas das amostras.

Fonte: Elaborado pelos autores.

A partir desse gráfico pode-se verificar que a amostra temperada possui baixa dureza, devido ao baixo teor de carbono presente na austenita que originou a martensita. A amostra temperada na zona intercrítica possui uma dureza intermediária, pois apesar de apresentar uma martensita originada de uma austenita rica em carbono está sobre uma matriz de ferrita primária dúctil e cercada de bainita.

\section{CONCLUSÃO}

Com esse trabalho foi possível concluir que a amostra temperada na zona intercrítica, apesar de possuir ilhas de martensita proveniente de grãos de austenita mais rico em carbono que a amostra temperada a $930 \stackrel{\circ}{\circ}$ possui dureza menor, pois apresentou bainita em sua microestrutura. 
Observou-se, também, as diferentes microestruturas provenientes desses tratamentos, a amostra normalizada apresentou uma matriz ferrítica com grãos de perlita. A amostra temperada a $930^{\circ} \mathrm{C}$ apresentou uma microestrutura martensítica e a amostra temperada na zona intercrítica apresentou uma matriz ferrítica com grãos de bainita e martensita.

\section{AGRADECIMNTOS}

Ao Laboratório de Caracterização de Materiais (LACAM - UFC) pela disponibilidade do forno para os diferentes tratamentos térmicos e microscópio óptico para a obtenção das imagens das microestruturas presentes neste trabalho.

Ao Laboratório de Pesquisa e Tecnologia em Soldagem ( LPTS) por permitir a utilização do microscópio eletrônico de varredura utilizado na obtenção das imagens de alta magnificação.

Ao Aluno de Doutorado Emerson Miná, pelas imagens de MEV.

\section{REFERÊNCIAS}

1 CALLISTER, W. D. Fundamentos de ciência e engenharia de materiais: uma abordagem integrada. 2 ed. Rio de Janeiro: LTC, 2006.

2 COSTA E SILVA, A. L. MEI, P. R. Aços e ligas especiais. 3 ed. São Paulo: Edgar Blucher, 2010.

3 CHIAVERINI, V. Aços e Ferros Fundidos. 7ed. Livros ABM, 1996.

4 ASM HANDBOOK. Volume 1. Properties and Selection: Irons, Steels, and High Performance Alloys, v. 2, 2009.

5 ASM METALS HANDBOOK. Volume 4- Heat Treating. ASM International,1991. 